\title{
What They Want And How They Want It: Students Expectations Of ESL Curriculum At The Classroom Level
}

\author{
Thomas Tucker, Hankuk University of Foreign Studies, South Korea ${ }^{1}$
}

\begin{abstract}
The foundation of education is the curriculum which is used in the teaching/learning process. People have varying views in the field of curriculum. The question of what and how to teach has been around as long as education.

This paper takes a closer look at how a sample of university students studying English in South Korea feel about the curriculum they are presented. The goal was to ascertain the expectations of the students when it came to the curriculum they were presented with in class. Another aim was to determine whether they preferred a subject-centered or a learner-centered curriculum design method. The final objective was to see the benefits of their suggestions with regards to the materials and methods of presentation used in class.

After reviewing the responses, a clear theme came to light among both English major students and the students of other majors taking their required course. That theme is a more learner-centered classroom. The research led to looking at curriculum-transmitting, curriculum-developing, and curriculum-making at the classroom level.

Research suggests that aligning the class to the expectations of the students with regard to curriculum benefits the learning experience. This paper shows that students prefer that curriculum be based on a learner-centered design at the classroom level.
\end{abstract}

Keywords: Subject-Centered; Learner-Centered; Curriculum-Transmitting; Curriculum-Developing; CurriculumMaking

\section{INTRODUCTION}

(๑)

ne of the major areas of education is curriculum. Curriculum can mean different things to different people based on their philosophical foundations, values, and educational experience. For some it takes on a narrow definition and relates to the textbook or other physical materials used in the class. For others it has a very broad meaning related to the total experience of the learner. (Ornstein and Hunkins, 2009) Wherever one falls in this spectrum, curriculum and curriculum development play a crucial role in the student's classroom experience. Due to this factor, it is important when designing curriculum to take into account the students, pedagogy, and learning environment.

Just as there are different definitions of curriculum, there are several different designs to curriculum. These designs fall into three categories; subject-centered, learner-centered, and problem centered. (Ornstein and Hunkins, 2009, 206) Given the range of the curriculum field and the subjective nature of language, this paper will reflect a broad definition of curriculum involving the entire experience of the learner in the course. For the purpose of this research, a questionnaire was issued to university students studying in English as a Second Language classes,

\footnotetext{
1 This work was supported by Hankuk University of Foreign Studies Research Fund 2011
} 
specifically Practical English. The goal of the questionnaire was to see how the students feel about the current curriculum. The research will analyze which curriculum design matches with the expectations of the students possibly leading to motivation, and in turn more learning of the English language. Gross (1996) stated that, "Motivation is a key factor for effective teaching and learning, because motivation makes people do what they do. When students are motivated, their behaviour is directed toward a specific target, and is very purposive." (as sited in Shawer, Gilmore, and Banks-Joseph, 2008) From the results of the data, we will also look in to the method by which a teacher uses the material in the classroom.

There are three different approaches to this: one, the fidelity approach (curriculum-transmitter), two, the adaptation approach (curriculum-developer), and three, the enactment approach (curriculum-makers). (Shawer, Gilmore, and Banks-Joseph, 2009) These approaches are closely related to the pedagogy the teacher uses and directly affect the classroom environment. The broader purpose of the paper is to display some ideas as to how teachers can better present the material to the class there by evoking motivation and learning.

\section{CURRICULUM DESIGN CATEGORIES}

Once the person or team in charge of developing the curriculum has determined a philosophical foundation with regard to education, they have taken the first step in developing a curriculum design. When the developer clarifies their stance on how students learn and what students should learn, they are ready to move forward in developing a curriculum design based on these beliefs. "Curriculum design is concerned with the nature and arrangement of four basic parts: objectives, content, learning experience, and evaluation." (Ornstein and Hunkins, 2009,182 ) These four parts are the basis for some education administrators and teachers having a broad definition of curriculum. There are many components to consider when moving towards curriculum design. The numerous components that curriculum developers consider lead to three basic curriculum designs. Subject-centered, learnercentered, and problem-centered are the major design models used in education. (Ornstein and Hunkins, 2009, 206) All three of them have sub-models that vary in detail.

Subject-centered curriculum deals with content and knowledge acquisition as the main focus. The subjectcentered design is sometimes referred to as textbook-centered and has been the favourite of many educational systems around the world. In this approach Knowles stated, "...students gain mastery of subject matter predetermined by a set of "experts." Curriculum is organized around content units and the sequence of what is taught follows the logic of the subject matter." (as sited in Prevedel, 2003 para. 3) The schools have the power to make decisions on what will be taught in the classroom in this design.

Learner-centered designs are curriculum designs in which the student is the focus of the curriculum more so than the subject. (Ornstein and Hunkins, 2009, 197) In an article about the value and beliefs in curriculum, Prevedel provides a definition of learner-centered curriculum and the motives behind it. She states:

Students are involved in "developing instructional materials that respond to students' interests and respect their culture and prior learning." This definition sees students taking an active role in developing curriculum; the curriculum is based on their reasons for learning as well as what they bring with them into a learning situation. A more recent term, "learner-driven," better describes the dynamic nature students bring to curriculum and instruction. (2003)

The problem-centered design method, sometimes referred to as the critical approach, looks at education in terms of developing critical thinking and problem solving skills in conjunction with current social issues. Proponents of this design want to provide an education that will emancipate people from being oppressed via development of critical thinking and problem solving skills, thus making society more equal for everyone. (Prevedel, 2003) There are similarities with the learner-centered approach in that the learner works with the teacher to develop the curriculum. The problem-centered approach focuses on both content and the learner's personal development as a citizen. (Ornstein and Hunkins, 2009, 203) In this paper the problem-centered and learner-centered curriculum designs will be considered as one and the same because they both allow the students to have some control on the curriculum and the curriculum development. The approach will be called learner-centered for this paper. 


\section{PRESENTATION OF CURRICULUM}

There are a several ways that a teacher can present the curriculum to the students. These different approaches show the degree of influence teachers have over the curriculum once presented with it. In an article by Shawer et al. (2009) three different approaches teachers can take when dealing with curriculum at the classroom level were defined. In the first approach, teachers are considered curriculum-transmitters. Teachers deliver the curriculum provided without introducing supplementary material or making any adaptations. In the second approach, teachers are considered curriculum-developers. Curriculum-developers make significant adaptations to the prescribed curriculum by introducing new materials and topics. In the third and final approach teachers are considered curriculum-makers. Curriculum-makers develop curriculum without reference to the prescribed curriculum. (Shawer et al., 2009)

When looking at these approaches and relating them back to the curriculum design methods we can see that a curriculum-transmitter seems to be much more subject-centered, whereas curriculum-developers and curriculummakers fall into the learner-centered designs. In both the curriculum-transmitters and the curriculum-developers, the curriculum comes from an outside source. However, the curriculum-developers take a much more active role in the classroom as they adjust the material or bring in outside material to supplement the curriculum provided to them. Curriculum-makers can choose to use an external curriculum which is provided, but they take a more active role in adapting the material and in many cases develop their own material through interactions with the students.

\section{QUESTIONNAIRE AND PARTICIPANTS}

An anonymous questionnaire written in English was given to 80 students ranging in age from twenty to twenty-four years old studying at a well respected university in Korea. The survey consists of qualitative questions evoking answers based on the opinions of the students answering them. The results are not to determine which method is conclusively the best one for the ESL classroom, but to explore what the students expect or feel about the curriculum. The results will be tied into this paper to determine which method aligns with the students' expectations and offer benefit in the ESL environment. The results of the survey are outlined in detail below. The students were all enrolled in an English course though their departments and majors varied. Eleven surveys were discarded due to confused answers or the majority of the survey being left blank. Half of the students were English majors and the other half were non-English majors. One of the research questions was to learn whether there would be a difference in their responses based on status as an English major. After reviewing the students' responses there was no clear difference in their responses. Nearly $50 \%$ of all the students responded that they were taking English to get a better job. Due to this there is no division of the two groups in the discussions of the findings.

Table 1

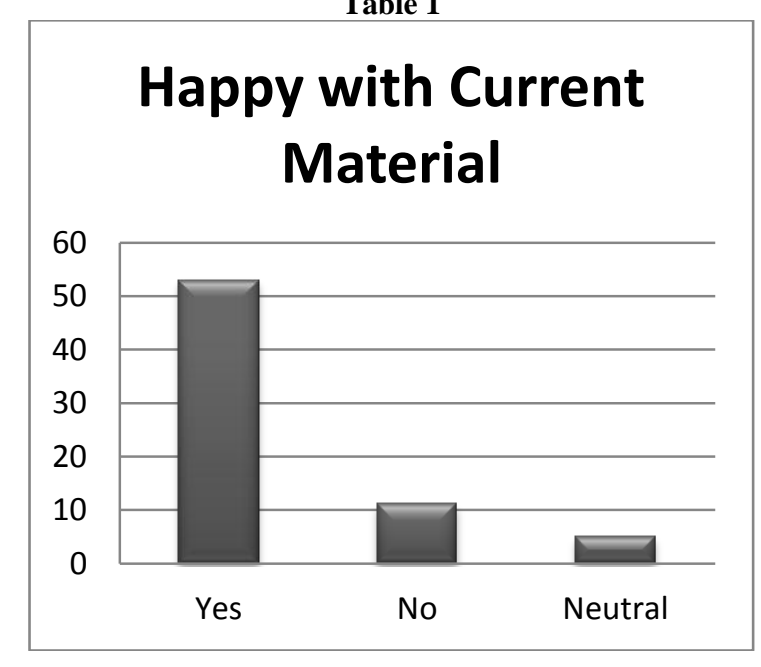




\section{DISCUSSION OF TABLE ONE}

The responses to the question of whether or not students were happy with the current curriculum content that they used in class show that $77 \%$ of the students are happy with the classroom materials. Thirty-six percent of the respondents who are happy with the material specifically mention that the use of various materials in the class. One student wrote:

\section{Yes! Various materials make me more interested.}

This student's instructor is using various materials, not just the book, in the class which makes it more interesting for many of the students. This instructor is using more of a curriculum-developer method in the classroom and offering a more interesting environment for the students. A different student's response taken from the questionnaire displays the same positive attitude to using supplementary materials that complement the textbook. This student wrote:

Yes. It really helped me to improve my English skill. Many materials about various topics were exciting.

These attitudes displayed by the students at this particular university mirror those of other English students from different schools. Here are a few examples from a study conducted by Shawer, et al. (2008); "The textbook is boring, other materials are more interesting."(Shawer et al., 2008, 17) Another student in that study said "she makes the course more interesting, but if she follows the textbook, it will be very boring and we will find it very difficult to learn." (Shawer et al., 2008, 17) The ESL students surveyed in Shawer's study and the students surveyed in this study feel the same way about the materials used in class. Many of them want to use various materials when learning the language.

A very small portion of the respondents, $15 \%$, said they were unhappy with the material. Half of the respondents who were unhappy with the material attributed their unhappiness to the textbook. Here are what two students said:

I don't like the book of Practical English, it isn't practical and is a little easy.

I think the idioms that you teach to us is really nice! Because it's real practical English. I think, the textbook is a little boring.

These students expressed a common attitude among those who are unhappy with the material. These comments regarding the book were the two most common responses as to the reasons for being discontented with the class material. The negative remarks regarding the book may reflect in a different way students' interest in multiple types of material. By using more supplementary material (curriculum-development), a teacher can overcome these obstacles in class.

When asked, many students said they would change nothing about the material, the thing that most students would change was adding more multimedia into the class. Students anecdotally reported to the researcher that they would like additional multimedia in the class and that it would help them learn in a more natural manner.

The small percentage of students unhappy with the book mentioned they would change the book when responding about changing the material. It is important to note that the Korean education system is a subjectcentered one. (Moon, 2007) It can be presumed that the students are comfortable with a subject-centered system in which the textbook is the central learning tool in the classroom because of their familiarity with it. The students' needs for a textbook were outlined in Shawer's et al. (2009) article ranging from offering structure, reassurance, and security to providing exam preparation and feedback to the students. (Shawer, 2009) According to Garinger, "A textbook can serve different purposes for teachers: as a core resource, as a source of supplemental material, as an inspiration for classroom activities, even as the curriculum itself." (Garinger, 2002, 1) The students' desire for a good grade and the dependence on the textbook as a means to that grade fit nicely into the benefits of students 
having a textbook as outlined by Shawer et al. (2009). However, this raises the question "what will help the students learn the language better instead of teaching to the tests?"

Table 2

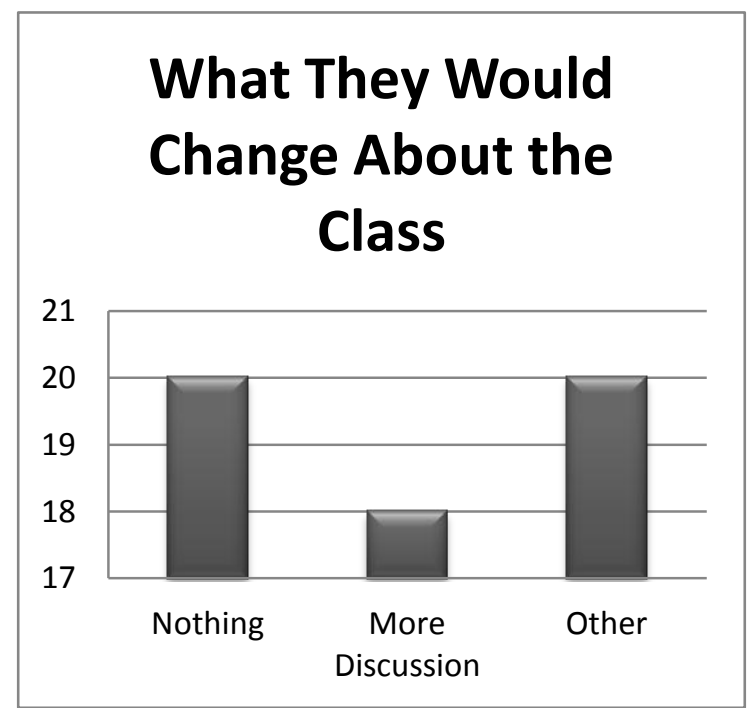

Table 3

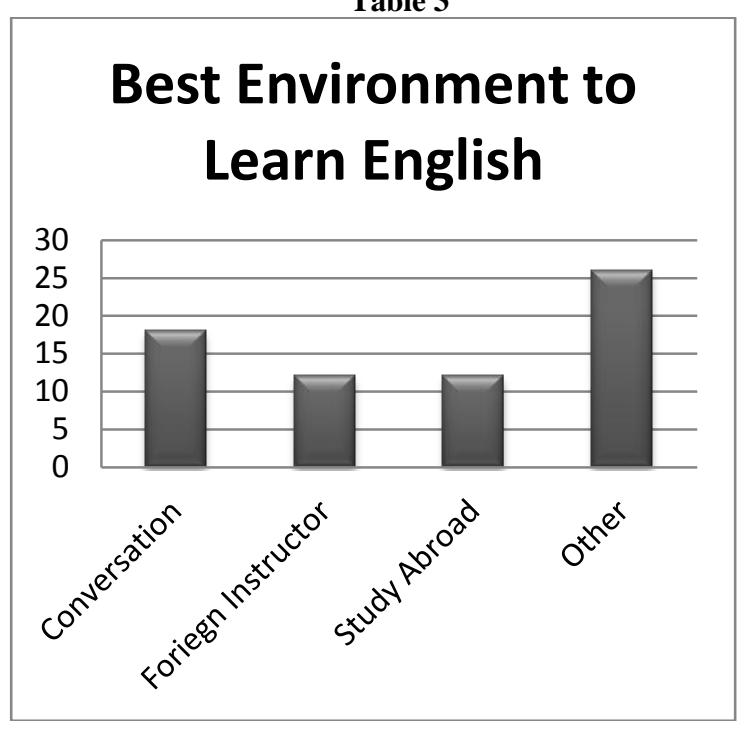

\section{DISCUSSION OF TABLE 2 AND TABLE 3}

People have varying ideas about what a curriculum entails. Having looked at what students might change about the material, the next step was to learn what the students would change about the class in general. Table 2 shows the respondents' answers to what they would change about the class whereas Table 3 shows what they perceive as the best environment in which to learn English in. The connection is that, in theory, the students would change the class to better suit their perceived optimal learning environment.

Thirty-four percent said they wouldn't change anything about the class in general. As seen in Table 1, many students were happy with the material. Many of the respondents who said they wouldn't change anything failed to give a reason why. The responses indicated that professors provided a broad range of material which students seemed to enjoy. Due to the various learning styles students have, it would be expected that some would be happy in the current class. The motivations behind learning might also play a part but this is inconclusive as a large majority stated that they were taking English classes to get a better job.

The second most frequent answer to the question of what they would change about the class was providing more discussion opportunities for the students. At $31 \%$, the number of students in this category nearly matched the ones who would not change anything. The following responses by a few students showed their opinions about having more discussion time in class:

I would want more class interaction between students as well as teachers.

Most of students are using English in passive, giving them more chance to speak would be good.

Talk with each other more often by doing games or activities.

These three students showed a desire to have more time to speak not only with the teachers but also with each other. Simich-Dudgeon (1998) state that research has provided evidence that collaborative talk is at the core of the learning experience. Another point that is made in the article is that teachers can use the discussion time to learn 
about the student's thoughts and feelings about the themes or topics they discuss and use this to develop learnercentered curricula. (1998) So, if a teacher expects to be a curriculum-developer at the classroom level, they must provide the students time to discuss topics with each other as a class or in small groups.

The third response mentioned the use of games to promote conversation among students. The use of games in some classrooms can be a controversial issue. Reese and Wells (2008) point out that some teachers and students see them as a waste of time while, others view them as a great way to promote conversation, learning, and motivation. They go on to suggest that a well designed game can be a valuable learning tool because games can act as a vehicle to engage students in conversations that will teach authentic conversational skills which textbooks often lack. Games also require students to use decision making skills and engage in a repetitive process utilizing the English learned. (Reese \& Wells, 2008) Games can be a fun way to promote competition, relaxation and learning. (Deesri, 2002) According to Avedon, the main reason games are an effective learning aid is that they motivate students, and students become immersed in the competitive aspect of the game making them work harder during the games. (as cited in Deesri, 2002). The South Korea education system is focused on the highly competitive higher learning entrance exams. (Seth, 2002) Games can use this inclination to competition to enhance learning in the English classroom.

Teachers might think students would change the class to better suit their optimal learning environment, and as Table 2 and 3 show, on some level they did. Students wanted more discussion in class and many of them said that the best environment to learn English is one in which conversation was promoted between teacher and student and amongst students themselves. One student's opinion was expressed in the following manner:

Where I actually can speak and practice in English would be the best environment.

In J. Williams' (2001) article on classroom conversation, she discusses how instructional conversations in class allow students to use the language as a means of improving their proficiency. (2001) This corresponds to what the student mentioned in the above statement. Providing time to practice conversational skills in class adds to the students' learning of the language.

When asked, $19 \%$ of students said that learning from a native English speaker is the best environment for learning the language. Students involved in a study in Japan conducted by Saito and Ebsworth (2004) suggested that the students liked learning native English expressions that a native English teacher brings to class. The students also saw value in learning about another culture. Some students in the study also said they preferred Japanese English teachers because they can sympathise with the students and offer explanations in Japanese when confronted with difficult concepts. (2004) A two-fold research study conducted by Arva and Medgyes in Hungary looked at the difference between native and non-native English teachers found that non-native English teachers, while fluent, could not match the native English speaking teachers (NEST) on any English language area of competency. (2000) They also found that: "the very fact that NESTs represented a different cultural heritage greatly enhanced the students' motivation, enabling them to move at the interface of two cultures." (Arva, and Medgyes, 2000, 369) However, it is inclusive to say one teacher is better than another based solely on their native language. Many more factors play into being a productive, language improving teacher.

Many of the students mentioned that studying abroad in an English speaking country is the best environment in which to learn English. In this approach to learning, students ideally are forced to speak English out of necessity and in turn learn the language. Table 3 shows a fairly large "Other" category with a wide variety of responses. The largest response to the question was an "English-only" environment. An English-only environment and studying abroad are vastly different in terms of exposure to the language. However, the goal in both situations is total immersion in the language. For this reason they were grouped together in the discussions of this data. Immersion as a means of learning a new language is not a new idea. Herbert Spencer, who some say started modern education with his progressive approach, noted that a student should learn a second language just as they learned their first, by being immersed in it. (Egan, 2002, 121) Egan writes "What we now call "immersion" methods were to displace the grammar-based method." (122) The research showed that many students thought this was the best environment for learning English. How effective is this though? In a study by Dwyer (2004) to ascertain the effectiveness of study abroad programs, she found that these programs have a large impact on students' lives in 
several areas including continued language use and academic attainment. She notes that this is a sustainable improvement. From the same study she wrote: "the results of this study would suggest that programs of at least 6 weeks duration can be enormously successful in achieving important academic, personal, career and intercultural development outcomes." (162) Her study in an immersion environment strongly suggests that the students who think an English-only environment or the more involved study abroad programs are great situations to learn English have good reason to believe so. A teacher who develops curriculum at the classroom level can provide a stronger multifaceted immersion program for those students who do not have the opportunity to study abroad. That same teacher can prepare those who will participate in a study abroad program with regular intervals of immersion.

Many of the things the students would change about their class, or believe is the best environment to learn English, can be achieved by means of the professor who is developing the curriculum in the classroom to fit the tastes of the students. The responses indicated that professors whose students who did not wish to change anything were already developing curriculum in the class.

\section{LIMITATIONS}

One limitation to this study was the sample size. The research was conducted on a small sample size at one university. The research was not able to conclusively show that adhering to the students' expectations in class was the best method. Instead, it noted what the students report they want. The students' seemed to want to have a professor who was developing curriculum at the classroom level. The supporting evidence shows that there are some benefits to the things the students mentioned.

Another limitation was that the questionnaire was in English, not the students' native language. It is possible that some of the students misunderstood some of the questions. This is something that should be considered when looking at the results.

Looking at Table 2, about $20 \%$ of the students in the "Other" category mentioned that the classes were too big. They indicated that they preferred smaller classes, and some mentioned that the classes were too large for them to have a chance to use English in class. Two students said,

Usually there are too many people in a class. 40 is too much for learning.

Class people number, too many to talk to each other.

It should be noted that the first student quote above about class size is exaggerated. At this particular university, class size is capped at 30 students. This topic is something that should be looked at more closely in future studies. There are many variables in providing the optimal learning environment at which this study does not look closely, class size being one of them.

There was no discernable difference in the responses from the English majors and the non-English majors, but the question opens the door for more research. However, this study utilized a small sample of students from one university in Korea. This topic is one in which a more detailed look might unlock the doors to providing a more engaging learning environment based on a student's major.

A broad definition of curriculum was used to build the survey. Curriculum includes so much more than the concrete materials used in class. The classroom environment (students, teacher, and pedagogy) plays a very important role in the curriculum. The scope of curriculum is in fact a limitation. There are a plethora of variables in the learning environment which need to be considered alongside curriculum.

\section{DISCUSSION}

The starting point and the motivation behind the research was to determine the students' expectations when it came to the curriculum with which they learn a foreign language, specifically English. The research in essence set out to determine if the student subjects preferred a subject-centered, learner-centered, or problem-centered 
curriculum design by questioning the students themselves. When questioned, students did not mention wanting to be involved directly in the selection of material for the class but instead seemed to prefer a top-down approach to the selection of material. They indicated a preference for subject-centered curriculum. Very few students mentioned the textbook in their responses and none showed a desire to be involved in the process. From reading the responses, at first glance it seemed that the students liked a subject-centered approach, which would make sense after working their way through such an approach since the time they started school. ( Seth, 2002) The students wanted a variety of material, more opportunity to work in groups, and above all more opportunity to have class discussion about issues relevant to them. The students who were surveyed wanted a curriculum-developer, someone who would add to the textbook with relevant supplementary material to enhance the class.

\section{CONCLUSION}

There was no indication from the responses to the survey questions that the students wanted a true learnercentered approach to curriculum design. That is the students did not want to be actively involved in the curriculum decisions. What did become apparent was the fact the students wanted some aspects of the learner centered design at the classroom level. The students' responses indicated that they want an active classroom that is relevant to them which is a part of Prevedel's definition of learner-centered curriculum design. The responses quoted throughout the research signify that the students want various materials and opportunity for conversations and discussions within the classroom. The students did not mention changing the books but they clearly responded that they wanted more than just the books. Looking back to the definition of a curriculum-developer from Shawer et al. (2009), curriculum-developers are teachers who make significant adaptations to the prescribed curriculum by introducing new materials and topics, we can see the connection between the sample students' desires and a curriculumdeveloper's action. The supporting research discussed shows that there are benefits in implementing the students' suggestions in the classroom.

\section{ACKNOWLEDGEMENTS}

This work was supported by Hankuk University of Foreign Studies Research Fund 2011.

\section{AUTHOR INFORMATION}

Thomas Tucker is a full-time instructor of Practical English at Hankuk University of Foreign Studies in South Korea. He is also a Masters of Education student at the University of New Brunswick in Canada. He is focusing his studies on curriculum. He is available to be contacted at thomastucker82@ hotmail.com.

\section{REFERENCES}

1. Arva, V., \& Medgyes, P. (2000). Native and non-native teachers in the classroom. System, 28(3), 355-72.

2. Deesri, A. (2002). Games in the ESL and EFL Class. The Internet TESL Journal, Vol. VIII, No. 9.

Retrieved from: http://iteslj.org/Techniques/Deesri-Games.html

3. Dwyer, M. M. (2004). More is better: The impact of study abroad program duration. Frontiers: The Interdisciplinary Journal of Study Abroad, 10, 151-163.

4. Egan, Kieran (2002) Getting It Wrong From The Beginning: Our Progressivist Inheritance From Herbert Spencer, John Dewey, and Jean Piaget. Yale University Press New Haven \& London.

5. Garinger, Dawn (2002) Textbook Selection for the ESL Classroom. Center For Applied Linguistics. Eric Clearinghouse on Languages and Linguistics. EDO-FL-02-10.

6. Moon, Y. (2007). Education reform and competency-based education. Asia Pacific Education Review, 8(2), 337-341.

7. Ornstein, A.C., \& Hunkins, F.P. (2008). Curriculum Foundations, Principles, and Issues. $5^{\text {th }}$ Edition. Old Tappan, NJ. Pearson Education (US).

8. Prevedel, A. (2003). Values and Beliefs: The World View Behind Curriculum. Focus on Basics Connecting Research and Practice. Volume 6, Issue C, 8-13

9. $\quad$ Reese, C., \& Wells, T. (2007). Teaching academic discussion skills with a card game. Simulation \& Gaming, 38(4), 546-555. 
10. Saito, H. (2004). Seeing english language teaching and learning through the eyes of japanese EFL and ESL students. Foreign Language Annals, 37(1), 111-124.

11. Seth, M. (2002). Education Fever: Society, Politics, and the Pursuit of Schooling in South Korea. University of Hawai'i Press (US)

12. Shawer, S. F., Gilmore, D., \& Banks-Joseph, S. (2008). Student cognitive and affective development in the context of classroom-level curriculum development. Journal of the Scholarship of Teaching and Learning, $8(1), 1-28$.

13. Shawer, S., Gilmore, D., \& Banks-Joseph, S. (2009). Learner-driven EFL curriculum development at the classroom level. International Journal of Teaching and Learning in Higher Education, 20(2), 125-143.

14. Simich-Dudgeon, C., \& National Clearinghouse for, B. E. (1998). Classroom strategies for encouraging collaborative discussion Directions in Language and Education.

15. Williams, J. A. (2001). Classroom conversations: Opportunities to learn for ESL students in mainstream classrooms. Reading Teacher, 54(8), 750-57. 


\section{NOTES}

